\title{
Study on thermal curing motivating volcanic activity of rich-silicon IOTP
}

\author{
Zhigang Zhu ${ }^{1, a}$, Shunkai $\mathrm{Li}^{1, \mathrm{~b}}$, Beixing $\mathrm{Li}^{2, \mathrm{c}}$ \\ ${ }^{1}$ CCCC Wuhan Harbour Engineering Design And Research Co., Ltd, Wuhan, 430040, China. \\ ${ }^{2}$ State Key Laboratory of Silicate Materials for Architecture, Wuhan University of Technology, \\ Wuhan,430070, China. \\ a312378964@qq.com, ${ }^{b}$ 331052860@qq.com, ${ }^{c}$ libx0212.126.com.
}

\begin{abstract}
Keywords: Thermal curing; iron ore tailing; volcanic activity; mortar; autoclaved.
Abstract: In order to study the influences of different thermal curing methods on volcanic activity and mechanism of rich-silicon iron ore tailing powder (IOTP). Four different specific surface area of IOTP cured in different conditions was tested, at the same time, the strength, pore size distribution and hydration product was measured. Test results show that IOTP do not have activity cured by room temperature, it shows different degrees of volcanic activity cured by thermal conditions, especially in autoclaved condition. Hot-wet curing systems can obviously reduce the porosity and pore diameter size of IOTP mortars, improve the compactness of hydration products at the same time, the autoclaved curing systems is the best. Cured in autoclaved condition, the strength of IOTP mortars is the highest when the dosage of IOTP is $10 \%$, but the pore size distribution is the best when the content of IOTP is $30 \%$.
\end{abstract}

\section{Introduction}

The physical and chemical properties of IOT are similar with some building materials, many researches about comprehensive utilization of IOT have been carried out in recent years[1], such as using IOT as building aggregates and binding materials, recovering valuable metals, soil conditioner, reclamation[2-9]. The particle size of IOT is smaller and smaller along with the improvement of mineral processing technology, and the superfine IOT is no longer suitable for some building products[10]. The comprehensive utilization of IOT is only about $17 \%$ in China which is far below the average in western developed countries, it is necessary to explore more efficient ways to deal with IOT.

In view of some IOT are rich in $\mathrm{SiO}_{2}$, some researchers have studied the potential volcanic activity and value of rich-silicon IOT. YI Zhonglai[11] heated IOT in $700^{\circ} \mathrm{C}$ condition and milled to $400 \mathrm{~m}^{2} / \mathrm{kg}$, after that the IOT powder was mixed with clinker, gypsum, slag as binding materials. NI Wen[12] used some microscopic methods such as IR and SEM to test the crystal shape change of IOT, the results showed mechanical grinding was useful for stimulating the activity of IOT but the activity is very low. LI Beixing[13] studied the influence of curing systems on the activity of IOT, it proved that only the autoclave curing condition could stimulate the activity of IOT in concrete. FENG Xiangpeng[14] studied the influence of red mud on the thermal activation of IOT, the results showed the red mud can partly inspire the activity.

So many researches judged the activity of IOT only depend on the $28 \mathrm{~d}$ strength ratio and lose sight of the filling effect when powders get high specific surface area, they failed to distinguish the filling effect and volcanic activity in concrete. In this paper, inert quartz powder is introduced as correction standard, the volcanic activity of IOTP in different thermal curing conditions were tested through the strength, pore size distribution and hydration product, judged by comparing the changes 
under similar specific surface.

\section{Experiment}

\section{Materials}

The 52.5 ordinary Portland cement is from Huaxin, its physical properties and chemical composition are shown in table 1 and table 2. The IOT is from Miyun area, its main chemical composition is $\mathrm{SiO}_{2}$ and it belongs to rich-silicon IOT, the main mineral composition are quartz, feldspar minerals and magnetite, all of them are shown in table 2 and figure 1 . The $\mathrm{SiO}_{2}$ content of inert quartz sand is more than $90 \%$. The water is tap water from Wuhan city. Grinding agent is melamine and quality content is $0.035 \%$.

Table 1 The basic physical properties of cement

\begin{tabular}{ccccccccc}
\hline \multirow{2}{*}{$\begin{array}{r}\text { Water requirement of } \\
\text { normal consistency/\% }\end{array}$} & \multicolumn{2}{c}{ Setting time/min } & \multicolumn{3}{c}{$\begin{array}{c}\text { Compressive } \\
\text { strength/MPa }\end{array}$} & \multicolumn{3}{c}{ Flexural strength /MPa } \\
\cline { 2 - 10 } & Initial & Fianl & $3 \mathrm{~d}$ & $7 \mathrm{~d}$ & $28 \mathrm{~d}$ & $3 \mathrm{~d}$ & $7 \mathrm{~d}$ & $28 \mathrm{~d}$ \\
27.6 & 104 & 176 & 30.0 & 48.5 & 55.2 & 5.7 & 8.8 & 9.5 \\
\hline
\end{tabular}

Table 2 The chemical composition of cement and IOT(\%)

\begin{tabular}{cccccccccc}
\hline Name & $\mathrm{SiO}_{2}$ & $\mathrm{Al}_{2} \mathrm{O}_{3}$ & $\mathrm{Fe}_{2} \mathrm{O}_{3}$ & $\mathrm{MgO}$ & $\mathrm{CaO}$ & $\mathrm{SO}_{3}$ & $\mathrm{Na}_{2} \mathrm{O}$ & $\mathrm{K}_{2} \mathrm{O}$ & $\begin{array}{c}\text { Los } \\
\mathrm{s}\end{array}$ \\
\hline Cement & 19.95 & 5.06 & 3.34 & 2.54 & 63.30 & 2.29 & 0.14 & 0.53 & 1.09 \\
IOT & 65.27 & 7.46 & 11.80 & 5.27 & 3.80 & 0.24 & $/$ & $/$ & 2.13 \\
\hline
\end{tabular}

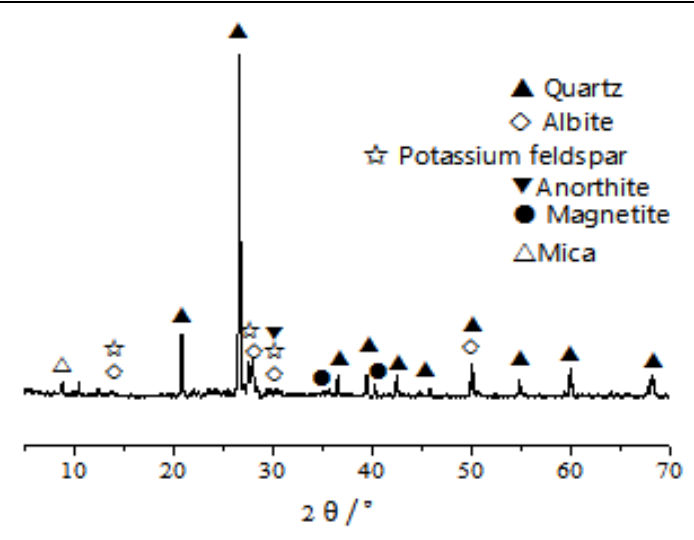

Fig 1 The XRD pattern of IOT

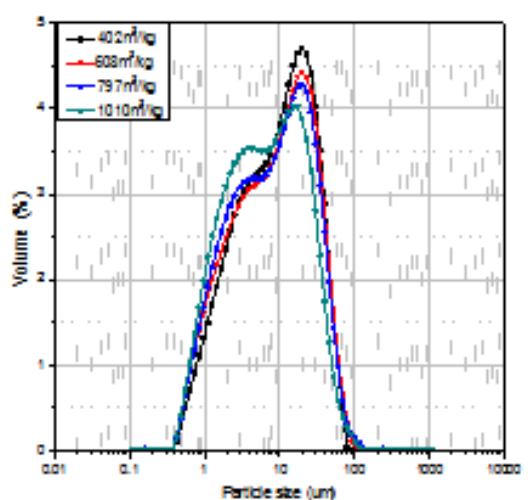

(a) Quartz powder particle

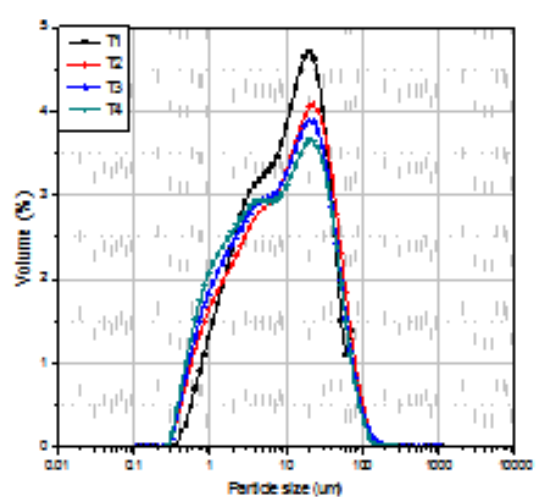

(b) Iron ore tailing powder particle

Fig.2 Particle size distribution graph of different powder 
Table 3 Particle size distribution data of different powder

\begin{tabular}{cccccccc}
\hline$/ \mathrm{m}^{2} \cdot \mathrm{kg}^{-1}$ & $\begin{array}{c}<1 \mu \mathrm{m} / \\
\%\end{array}$ & $\begin{array}{c}1-10 \mu \mathrm{m} / \\
\%\end{array}$ & $\begin{array}{c}10-30.2 \mu \mathrm{m} \\
/ \%\end{array}$ & $\begin{array}{c}>30.2 \mu \mathrm{m} / \\
\%\end{array}$ & $\mathrm{D}_{10} / \mu \mathrm{m}$ & $\mathrm{D}_{50} / \mu \mathrm{m}$ & $\mathrm{D}_{90} / \mu \mathrm{m}$ \\
\hline $\mathrm{Q}(402)$ & 3.57 & 45.55 & 35.07 & 15.81 & 1.659 & 10.331 & 37.092 \\
$\mathrm{~T} 1$ (410) & 3.93 & 39.74 & 32.82 & 23.51 & 1.403 & 12.611 & 49.906 \\
$\mathrm{Q}(608)$ & 4.70 & 46.08 & 33.07 & 16.15 & 1.433 & 9.696 & 37.989 \\
$\mathrm{~T} 2(595)$ & 6.64 & 41.65 & 30.23 & 21.48 & 1.257 & 10.755 & 47.515 \\
$\mathrm{Q}(797)$ & 4.71 & 48.19 & 32.13 & 14.97 & 1.403 & 8.896 & 36.727 \\
$\mathrm{~T} 3(813)$ & 7.50 & 44.02 & 29.27 & 19.01 & 1.150 & 9.273 & 44.122 \\
$\mathrm{Q}(1010)$ & 5.31 & 53.78 & 30.42 & 10.49 & 1.293 & 7.033 & 30.894 \\
$\mathrm{~T}(1001)$ & 8.78 & 45.06 & 27.62 & 18.00 & 1.037 & 8.171 & 42.756 \\
\hline
\end{tabular}

\section{Preparation and tests of powder}

The powder is made by ball mill which size is SM $5500 \mathrm{~mm} \times 500 \mathrm{~mm}$, in this paper, the $400 \mathrm{~m}^{2} / \mathrm{kg}, 600 \mathrm{~m}^{2} / \mathrm{kg}, 800 \mathrm{~m}^{2} / \mathrm{kg}, 1000 \mathrm{~m}^{2} / \mathrm{kg}$ represents $400 \pm 20 \mathrm{~m}^{2} / \mathrm{kg}, 600 \pm 20 \mathrm{~m}^{2} / \mathrm{kg}, 800 \pm 20 \mathrm{~m}^{2} / \mathrm{kg}$, $1000 \pm 20 \mathrm{~m}^{2} / \mathrm{kg}$ respectively. Specific surface area is tested by BET surface area, powder particle size is tested by Mastersizer 2000 laser particle size analyzer made by England, the activity of IOT is tested by China GB/T12597-2005 standard and GB2847-2005-T standard.

\section{Preparation of mortars and curing systems}

Preparation of mortars is according to the GB/T17671-1999, cement-sand ratio is 1:3, water-cement ratio is 0.5 , cement is replaced $30 \%$ by IOT powder or quartz powder, the size of mortar specimen is $40 \mathrm{~mm} \times 40 \mathrm{~mm} \times 40 \mathrm{~mm}$. The formed specimen are cured under room temperature which relative humidity is above $95 \%$ for about $24 \mathrm{~h}$, then ejected and cured in different ways till to defined period.

Table 4 Four different curing systems

\begin{tabular}{ccc}
\hline Curing Name & Curing systems & Age/d \\
\hline Standard & Standard curing & $3 、 28$ \\
Hot water & $90^{\circ} \mathrm{C}$ hot water for $2 \mathrm{~d}+$ standard curing & $3 、 28$ \\
High temperature & $90^{\circ} \mathrm{C}$ heat water for $1 \mathrm{~d}+200^{\circ} \mathrm{CH}$ High temperature for $8 \mathrm{~h}+$ standard curing & $3 、 28$ \\
Autoclave & $90^{\circ} \mathrm{C}$ heat water for $1 \mathrm{~d}+1.3 \mathrm{MPa}$ autoclave for $6 \mathrm{~h}+$ standard curing & $3 、 28$ \\
\hline
\end{tabular}

\section{Microscopic analysis}

Hardened slurry is tested by D/MAX-RB target $\mathrm{x}$-ray diffraction equipment made by Japanese RIGAKU company, the test conditions: $\mathrm{Cu}-\mathrm{K}$ alpha $(40 \mathrm{kV} / 200 \mathrm{~mA})$, scanning speed is $8^{\circ} / \mathrm{min}$, scanning range is $5^{\circ} \sim 70^{\circ}$, Step width is $\Delta 2 \theta \leq \pm 0.02^{\circ} /$ Step. Samples preparation method: samples are from center area of mortars and hydration stopped by anhydrous ethanol, the size of samples is below $75 \mathrm{um}$ and must be dried in $60^{\circ} \mathrm{C}$ vacuum dryer till to constant weight before test.

The model of SEM equipment is JSM-5610LV and made by Japanese Electronics Corporation. Samples preparation method: samples are from center area of mortars and hydration stopped by anhydrous ethanol, samples are dried in $40^{\circ} \mathrm{C}$ condition till to constant weight.

The pore structure is tested by Autopore III9220 made by America, measuring range is $0.003 \mu \mathrm{m} \sim 360 \mu \mathrm{m}$, maximum working pressure is $414 \mathrm{MPa}$. Samples preparation method: samples are from center area, hydration stopped by anhydrous ethanol and dried in the condition below $90^{\circ} \mathrm{C}$ till to constant weight before test. 
The model of IR equipment is Nexus made by American Thermo Nicolet company. All the samples are dried in the $60^{\circ} \mathrm{C}$ condition till to constant weight before test.

\section{Results and discussion}

\section{Influence of thermal curing systems on the mortar strength with IOTP}

Figure 3 is about the influence of thermal curing system on $28 \mathrm{~d}$ strength. The results show that, the strength of IOT mortars is lower than the strength of quartz mortars in room temperature condition. When specimen cured by hot water, high temperature or autoclave, the strength of IOT mortars is higher than the strength of quartz mortars. Especially when specific surface area of IOT powder is $813 \mathrm{~m}^{2} / \mathrm{kg}$ and in autoclave condition, the strength of IOT mortars is even higher than the strength of cement mortars.

It is known in section 2.1, the particle size distribution of IOT powder and quartz powder are similar and the strength of quartz mortars is higher than the strength of IOT mortars in room temperature condition. However, when mortars are cured by thermal curing condition, the strength of IOT mortars is higher than the strength of quartz mortars. It can be explained by that thermal curing system can stimulate the volcanic activity of IOT in concrete, the most efficient way is cured in autoclave condition and strength reaches the highest values when specific surface area is $813 \mathrm{~m}^{2} / \mathrm{kg}$, all of the rest tests depend on the same specific surface area.

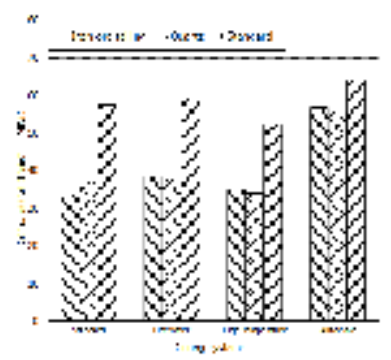

(a) $410 \mathrm{~m}^{2} / \mathrm{kg}$

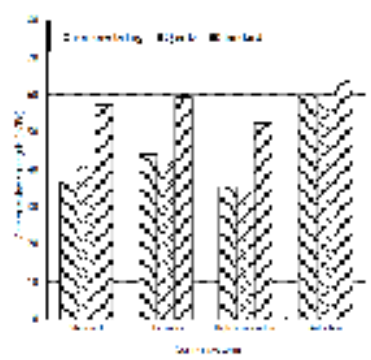

(b) $595 \mathrm{~m}^{2} / \mathrm{kg}$

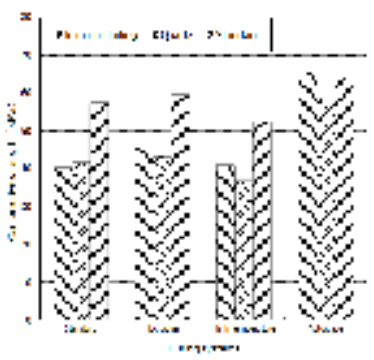

(c) $813 \mathrm{~m}^{2} / \mathrm{kg}$

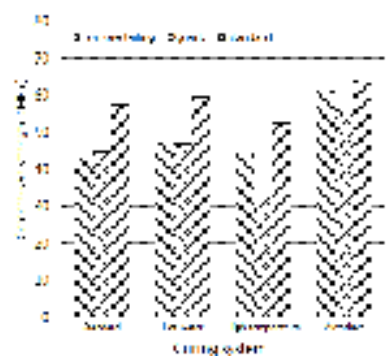

(d) $1001 \mathrm{~m}^{2} / \mathrm{kg}$

Fig. 3 The influence of curing system on $28 \mathrm{~d}$ compressive strength

\section{Influence of thermal curing systems on pore structure of mortars}

Generally, pores in concrete can be divided into three types, capillary pore, gel pore and layers pore. With the increase of hydration products in slurry, the content of capillary pores will decrease and the content of gel pores and layers pores will increase[15]. WU Zhongwei and some others[16,17] divide pores into four categories according to the influences on mechanical properties and durability in concrete, harmless pore $(<20 \mathrm{~nm})$, less harm pore $(20 \sim 100 \mathrm{~nm})$, harmful pore (100 200nm) and much harm pore $(>200 \mathrm{~nm})$.

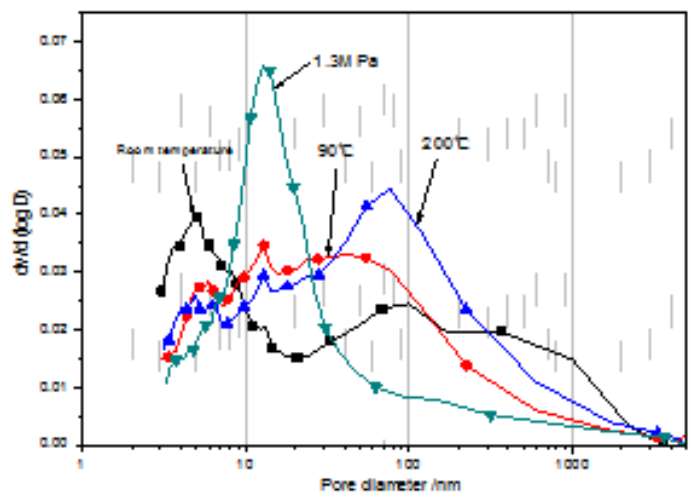

Fig.4 Pore size distribution pattern under different curing systems 
Table 5 Pore size distribution data under different curing systems

\begin{tabular}{cccccc}
\hline \multirow{2}{*}{ Curing systems } & \multicolumn{5}{c}{ Content of pore (\%) } \\
\cline { 2 - 5 } & $<20 \mathrm{~nm}$ & $20 \sim 100 \mathrm{~nm}$ & $100 \sim 200 \mathrm{~nm}$ & $>200 \mathrm{~nm}$ & Total porosity \\
\hline Room temperature & 63.49 & 15.30 & 1.97 & 19.22 & 14.1267 \\
Hot water & 61.63 & 22.37 & 2.39 & 13.61 & 13.5080 \\
High temperature & 50.96 & 24.03 & 2.9 & 22.11 & 15.6035 \\
1.3MPa autoclaved & 72.20 & 13.32 & 1.18 & 13.30 & 11.4888
\end{tabular}

Figure 4 and table 5 are about the pore structure in different curing conditions. The results shows that, hot water curing and autoclave curing can improve the pore structure of cement mortar, not only by reducing the total porosity and the number of damage hole, but also by increasing the number of harmless hole. But specimen cured by high temperature are not good, the total porosity and dangerous pores $(>20 \mathrm{~nm})$ all increase, it indicates high temperature will damage mortar's inner instruct, previous strength also appears the same result. This can be interpreted as high temperature curing system causes non-uniformity of hydration products, at the same time accelerated evaporation of free water forms a large number of connected pores.

\section{Influence of thermal curing system on hydration}

It can be seen from figure 5, slurry cured by standard condition has some $\mathrm{Ca}(\mathrm{OH})_{2}$, poorly and evenly distributed CSH gel, erosion acreage of the aggregate surface is little. Slurry cured by $90^{\circ} \mathrm{C}$ hot water appears lots of corrugated $\mathrm{CSH}$ gel, the part of acicular crystal is CHS gel, its structure is relatively even, gel overlays of each other. Slurry cured by high temperature condition has some tobermorite(coral shape part), but the hydration products are uneven distribution and different thickness. However, slurry cured by autoclave condition has lots of even and compact hydration products, from figure (d) can see a large area of hard CSH gel.

It is visible that thermal curing conditions have a positive effect on accelerating the hydration rate and expending the content of $\mathrm{Ca}(\mathrm{OH})_{2}$, high temperature curing system also plays the same role but likely destroy the even distribution of hydration products.

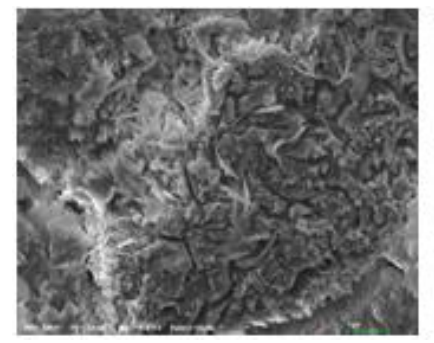

(a) Standard

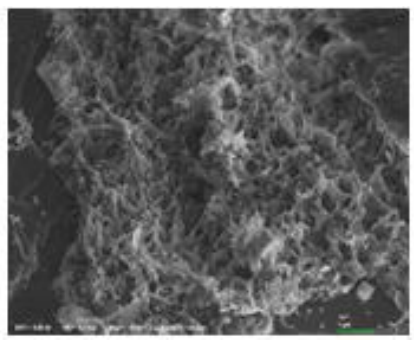

(b) Hot water

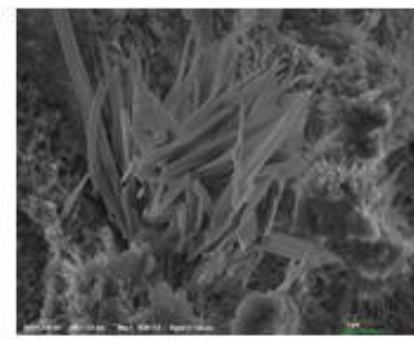

(c) High temperature

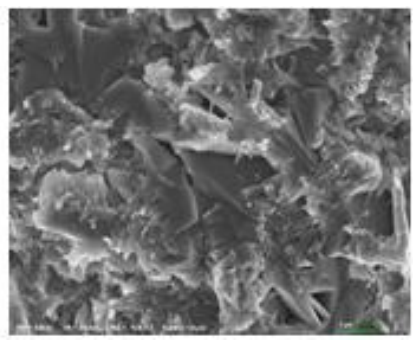

(d) Autoclave

Fig.5 Influence of curing system on morphology of hydration

\section{The influence of autoclaved curing system on hydration characteristics}

Figure 6 is about SEM images of $28 \mathrm{~d}$ mortars which cured in autoclave curing condition. Figure (a) can be obviously found cement particles, $\mathrm{Ca}(\mathrm{OH})_{2}, \mathrm{CSH}$ gel and connected pores between hydration products, the structure of slurry is loose. Figure (b) can be found smaller cement particles, a small number of tobermorite, general $\mathrm{CSH}$ and hard $\mathrm{CSH}$ gel, $\mathrm{Ca}(\mathrm{OH})_{2}$ crystals almost can't be found. Figure (c) can not be found cement particles or $\mathrm{Ca}(\mathrm{OH})_{2}$ crystals, there are a lot of 
compact hard CSH gel. The results show that when specimen cured by autoclave, the volcanic activity of quartz powder and IOTP is motivated, a large sum of $\mathrm{Ca}(\mathrm{OH})_{2}$ crystal is consumed by active $\mathrm{SiO}_{2}$ and hard $\mathrm{CSH}$ gel is generated in this thermal condition. Comparing figure (b) with figure (c), figure (c) does not have $\mathrm{Ca}(\mathrm{OH})_{2}$, larger area of CSH gel, it indicated that IOTP have more motivated $\mathrm{SiO}_{2}$, the volcanic activity of IOTP is higher than quartz in autoclaved condition.

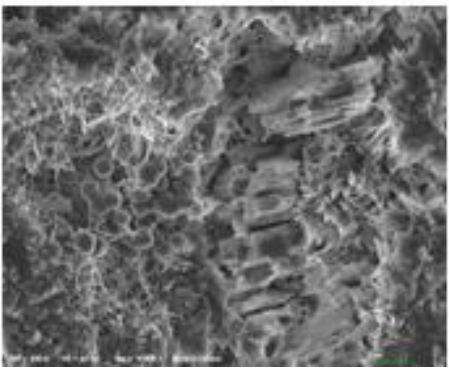

(a) $100 \%$ cement

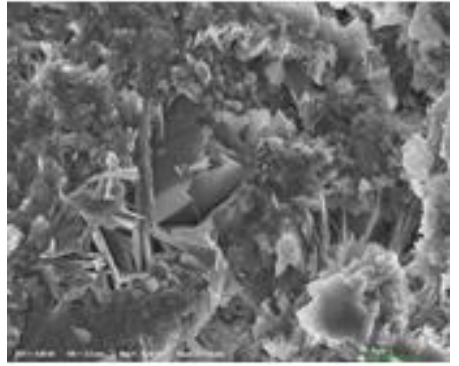

(b) $30 \%$ quartz powder $+70 \%$ cement

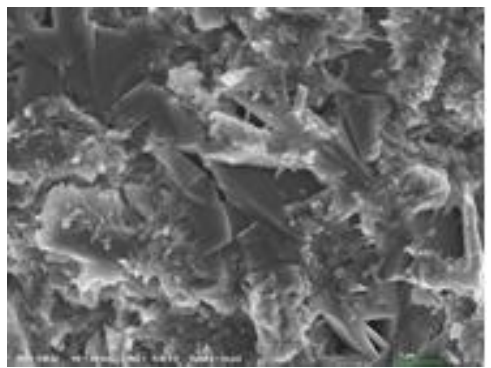

(c) $30 \%$ IOTP $+70 \%$ cement Fig.6 SEM patterns of mortars

The influence of IOTP content on mortars cured in autoclaved condition The influence of IOTPcontent on strength

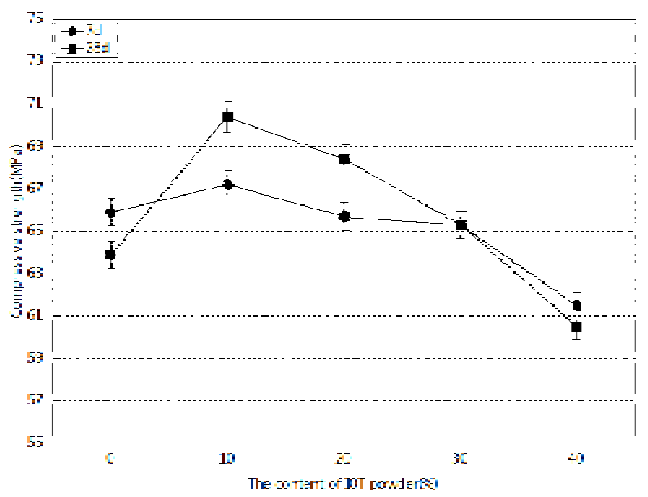

Fig.7 The influence of IOTP content on strength

Figure 7 is about the influence of IOTP content on compressive strength with the specific surface area of IOTP was $813 \mathrm{~m}^{2} / \mathrm{kg}$. For $7 \mathrm{~d}$ compressive strength, the intensity was increased when the IOTP content was $10 \%$, With IOTP content increased from $20 \%$ to $40 \%$, it presented the tendency of lower strength, and all were lower than control mortars'. For 28d compressive strength, when IOTP content was $10 \%$, the strength also was laced up close to $7 \mathrm{MPa}$ than control mortars', however, When IOTP dosage was $20 \%$ or $30 \%$, the strength declined but was also higher than the strength of control mortars. When IOTP content increased to $40 \%$, further reduce of strength and was lower than the strength of control mortars.

\section{Influence of IOT content on pore structure}

Figure 8 and table 6 are about the influence of different IOTP content on mortars' pore size distribution. The results showed that when the tail mineral powder content increased from 0 to $30 \%$, the content of much harm pore and total porosity decreased, the content of harmless pore increased, on behalf of pore distribution curve peak moved to the left, and the most compact structure when the dosage was $30 \%$. When the dosage increased to $40 \%$, the result was on the contrary, pore structure coarsened, total porosity increased, but the pore size distribution was better than control mortars. This may be caused by the low cement content and insufficient hydration slurry, the best dosage was $30 \%$ when the specific surface area of IOTP was $813 \mathrm{~m}^{2} / \mathrm{kg}$. 


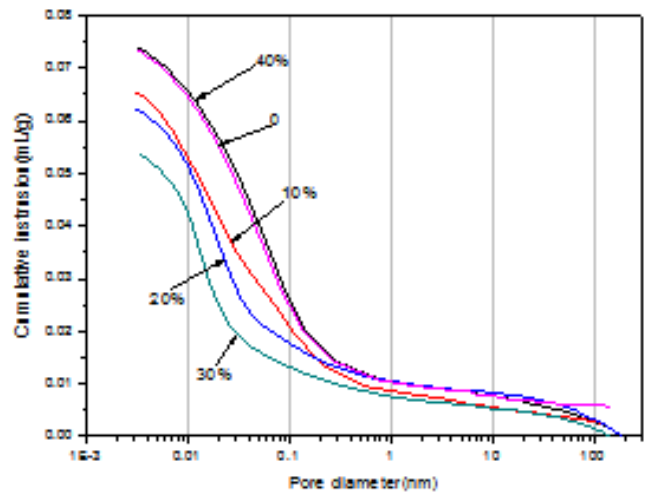

Fig.8 Pore size distribution pattern of different mortars Table 6 Pore size distribution data of different mortars

\begin{tabular}{cccccc}
\hline \multirow{2}{*}{$\begin{array}{c}\text { Content of } \\
\text { IOTP }\end{array}$} & $<20 \mathrm{~nm}$ & $20 \sim 100 \mathrm{~nm}$ & $100 \sim 200 \mathrm{~nm}$ & $>200 \mathrm{~nm}$ & Total porosity \\
\cline { 2 - 6 } & 41.67 & 38.05 & 2.93 & 17.35 & 15.5180 \\
0 & 61.07 & 22.36 & 2.67 & 13.80 & 13.5736 \\
$10 \%$ & 63.38 & 20.30 & 1.19 & 15.13 & 12.4953 \\
$20 \%$ & 13.32 & 1.18 & 13.30 & 11.4888 \\
$30 \%$ & 72.20 & 34.79 & 1.17 & 10.75 & 17.8758 \\
$40 \%$ & 53.29 & & & & \\
\hline
\end{tabular}

\section{Conclusions}

(1) In normal temperature condition, mortar strength increased with the growth of IOTP content, the compressive strength than even reached 75 , but its strength was lower than mortar strength with inert quartz powder. It showed IOTP does not have volcanic activity in normal temperature conditon, it is unreasonable to judging its activity by $28 \mathrm{~d}$ compressive strength ratio.

(2) In thermal curing condition, the mortar strength with IOTP was higher than mortar strength with quartz powder. Through SEM and MIP test methods scanning mortars cured by thermal curing systems, $\mathrm{Ca}(\mathrm{OH})_{2}$ almost disappeared in mortar added IOTP, content of $\mathrm{CSH}$ gel was increased, most compact mortar structure and large number of tobermorite. Its strength was even higher than control mortar strength when the specific surface area of IOTP was $813 \mathrm{~m}^{3} / \mathrm{kg}$. It proved that thermal curing can arouse activity of IOTP and autoclaved curing was the most effective mean.

(3) When the specific surface area of IOTP was $813 \mathrm{~m}^{3} / \mathrm{kg}$ and IOTP dosage increased from 0 to $30 \%$, mortar structure was refined, the filling effect and its active had a positive effect. But when the dosage increased to $40 \%$, sharply coarsening aperture structure appeared. It showed that IOTP had the effect of refining mortar aperture but the content was need to controlled.

\section{Conflict of Interests}

The authors declare that there is no conflict of interests regarding the publication of this paper.

\section{Acknowledgement}

This work was financially supported by the Natural Science Foundation Item of China(51372185). 


\section{References}

[1] Zhang S, Xue S, et al. Current situation and comprehensive utilization of iron ore tailing resources[J]. Journal of mining Science, 2006,42(4):403-408.

[2] ZHAO Sujing, FAN Junjiang, SU Wei. Utilization of iron ore tailings as fine aggregate in ultra-high performance concrete[J]. Construction and Building Materials, 2014,(50):540-548.

[3] HUANG Xiaoyan, Ravi Ranade, et al. Development of green engineered cementitious composites using iron ore tailings as aggregates[J]. Construction and Building Materials, 2013,(44):757-764.

[4] CHEN Mengyi, LI Beixing, et al. Reactive activity of iron ore tailings powder and its enhancement effect upon concrete[J]. Metal Mine, 2013,(5),164-168.

[5] Kumar S, Kumar R, Bandopadhyay A. Innovative methodologies for the utilization of wastes from metallurgical and allied industries[J]. Resource Conservation Recycle, 2006,(48):301-314.

[6] LI D X, GAO G L, et al. Preparation of nano-iron oxide red pigment powders by use of cyanided tailings[J]. Journal of Hazardous Materials, 2008,155(1-2):369-377.

[7] LIU Fengjuan, CHENG Jinshu, XIAO Jing. The composite and structure of Ta-Nb tailings glass-ceramics by sintering[J]. Journal of Wuhan University of Technology(Materials Science), 2003,25(9):26-28.

[8] Watson $\mathrm{J} \mathrm{H}$ P,Beharrell $\mathrm{P}$ A. Extracting values from mine dumps and tailings[J]. Miner Engineering, 2006,(19):1580-1587.

[9] Fall M, Benzaazouza M, Saa E G. Mix proportioning of underground cemented tailings backfill[J]. Tunnelling and Underground Space Technology, 2008,(23):80-90.

[10] XU Li, WU Hui, et al. Preparation for ultra-high strength concrete with tailings by using micro-ball effects[J]. Metal mine, 2010,(12):162-166.

[11] YI Zhonglai, SUN Henghu, LI Yu. Research on the influence of thermal activation for the cementitious activity of iron ore tailing[J]. Journal of Wuhan University of Technology, 2009, 31(12), 5-7.

[12] ZHENG Yongchao, NI Wen, et al. Mechanical activation of iron ore tailings and preparation of high-strength construction materials[J]. Journal of University of Science and Technology Beijing, 2010,32(4):504-508.

[13] LI Beixing, CHEN Mengyi, et al. Influence of curing system on the activity of silica-rich iron ore tailings and the pore structure of iron tailings-cement[J]. Journal of Wuhan University of Technology, 2013,35(8),1-5.

[14] FENG Xiangpeng, ZHANG Na, et al. Study on heat-activation property of iron ore tailing by red mud[J]. Metal mine, 2007,(10).132-136.

[15] ZHENG Keren, ZHOU Qingyan, HE Fuqiang. Influence of the blending quality of the mineral to the hole structure[J]. Shanxi Achitecture, 2007,33(22):181-182.

[16] LUO Bingbing, BI Qiaowei. Experimental study on the influence of pore structure of hybrid fibers self-compacting concrete on compressive strength $[\mathrm{J}]$. Bulletin of the Chinese Ceramic Society, 2012,31(3):626-630.

[17] YANG Yousheng. Relationship between pore structure of concrete and its frost durability degradation[J]. Highway Engineering, 2009,34,(4):151-154. 